LA W RENCE LIVERMORE NATIONAL LABORATORY
Comparison of CAISO-run Plexos output with LLNL-run Plexos output

A. Schmidt, C. Meyers, S. Smith

January 3, 2012 
This document was prepared as an account of work sponsored by an agency of the United States government. Neither the United States government nor Lawrence Livermore National Security, LLC, nor any of their employees makes any warranty, expressed or implied, or assumes any legal liability or responsibility for the accuracy, completeness, or usefulness of any information, apparatus, product, or process disclosed, or represents that its use would not infringe privately owned rights. Reference herein to any specific commercial product, process, or service by trade name, trademark, manufacturer, or otherwise does not necessarily constitute or imply its endorsement, recommendation, or favoring by the United States government or Lawrence Livermore National Security, LLC. The views and opinions of authors expressed herein do not necessarily state or reflect those of the United States government or Lawrence Livermore National Security, LLC, and shall not be used for advertising or product endorsement purposes.

This work performed under the auspices of the U.S. Department of Energy by Lawrence Livermore National Laboratory under Contract DE-AC52-07NA27344. 


\title{
Comparison of CAISO-run Plexos output with LLNL-run Plexos output
}

\author{
A. Schmidt, C. Meyers, S. Smith \\ Lawrence Livermore National Laboratory
}

\begin{abstract}
In this report we compare the output of the California Independent System Operator (CAISO) 33\% RPS Plexos model when run on various computing systems. Specifically, we compare the output resulting from running the model on CAISO's computers (Windows) and LLNL's computers (both Windows and Linux). We conclude that the differences between the three results are negligible in the context of the entire system and likely attributed to minor differences in Plexos version numbers as well as the MIP solver used in each case.
\end{abstract}

\section{Motivation}

High performance computing (HPC) has the potential to enable the timely solving of complex unit commitment problems in Plexos. The ability to parallelize Plexos runs could greatly increase both the total number of monthly scenarios analyzed as well as the complexity of the model than can be reasonably solved. Before LLNL can use their HPC systems to solve CAISO models, it is prudent to confirm that LLNL can reproduce CAISO's Plexos output.

The two MIP solvers used in the simulations presented here, XPress-MP and CPlex, seek to find a combination of values for both binary and continuous variables that minimize an objective function. This process involves creating a branch and bound tree that determines the order in which solutions are explored as well as which solutions can be eliminated. As soon as the MIP solver finds a solution that is within a specified tolerance of optimal, it stops exploring solutions. Put another way, the MIP solver does not find the global optimal solution, but rather finds a solution that satisfies the desired optimality tolerance. Because the MIP solver does not find the global optimal solution, it is expected that the generated solution for a given set of inputs could change if either the objective function formulation or the MIP solver were modified. Additionally, some MIP solvers can be run in "opportunistic mode" in which they use free computing processors to explore solutions that would otherwise get ignored (the LLNL runs analyzed in this report were run in deterministic mode, not opportunistic mode). While speeding up run time, this mode can result in solutions which differ slightly even for identical inputs.

Thus it is natural, when working with MIP solvers, to expect some variability in output for a variety of reasons. It is important, however, to examine this variability and ensure that the underlying solution qualitatively remains the same. This report aims to compare the outputs of the same Plexos model, when run on CAISO's computing environment, as well as two computing environments (Windows and Linux) at LLNL. 
Setup

LLNL ran the CAISO 33\% RPS Plexos model on two computing test beds - one on the Windows operating system and one on Linux. The model run was "Cost ProdCost 0603." Here we show a comparison between the 3 sets of output for the month of June (M06). Table 1 summarizes the relevant software components used by the 3 different computing environments:

\begin{tabular}{lll}
\hline & Plexos version used & MIP Solver used \\
\hline CAISO (Windows) & 6.104 R16 & Xpress-MP 20.00.11 \\
\hline LLNL (Windows) & 6.201 & Xpress-MP 21.01.07 \\
LLNL (Linux) & 6.202 R07 & Cplex 12.3 \\
\hline
\end{tabular}

Table 1.

\section{Results}

The first quantity used to compare the Plexos output files across the 3 computing environments was total generation of powerplants in GWh for the month of June. Figure 1 is a scatter plot of the total monthly generation calculated by the two LLNL-run Plexos simulations vs. the CAISO-run Plexos simulation. Each data point on the plot represents a single generator. Nearly every generator in the Plexos WECC model is included in this plot ${ }^{1}$. The units with the most generation, just under $1000 \mathrm{GWh}$, were producing on average about $1.3 \mathrm{GW}$ during the month. The sum of the generation for each generator is approximately $87,000 \mathrm{GWh}$ (this is for the entire WECC). The units with nearly $1000 \mathrm{GWh}$ of generation are "Gordon M. Shrum" and "PaloVerd3."

It is clear from the plot that the monthly generation from each generator is similar or identical whether the model is run on CAISO's computing environment or at LLNL. Most of the generators which show a noticeable discrepancy are ones with monthly generation below $300 \mathrm{GWh}$, with the exception of the "Intrmnt1" unit, which has a total monthly generation of $433 \mathrm{GWh}$ for the CAISO-run and LLNL/Linux-run simulation, but $456 \mathrm{GWh}$ for the LLNL/Windows-run simulation. The amount of monthly generation which shifts to another generator (relative to the CAISO-run model) is $0.38 \%$ of the total WECC generation in the Windows LLNL-run model and $0.50 \%$ of the total WECC generation in the Linux LLNLrun model.

\footnotetext{
${ }^{1}$ Three "generators" in the model, called "LFD_Only," "NP15_Dispatch," and "New Resources" are significantly off the scale of the Figure 1 plot. The generation for these 3 aggregated generators is identical for all 3 runs.
} 


\section{June comparison of CAISO/LLNL computed generation}

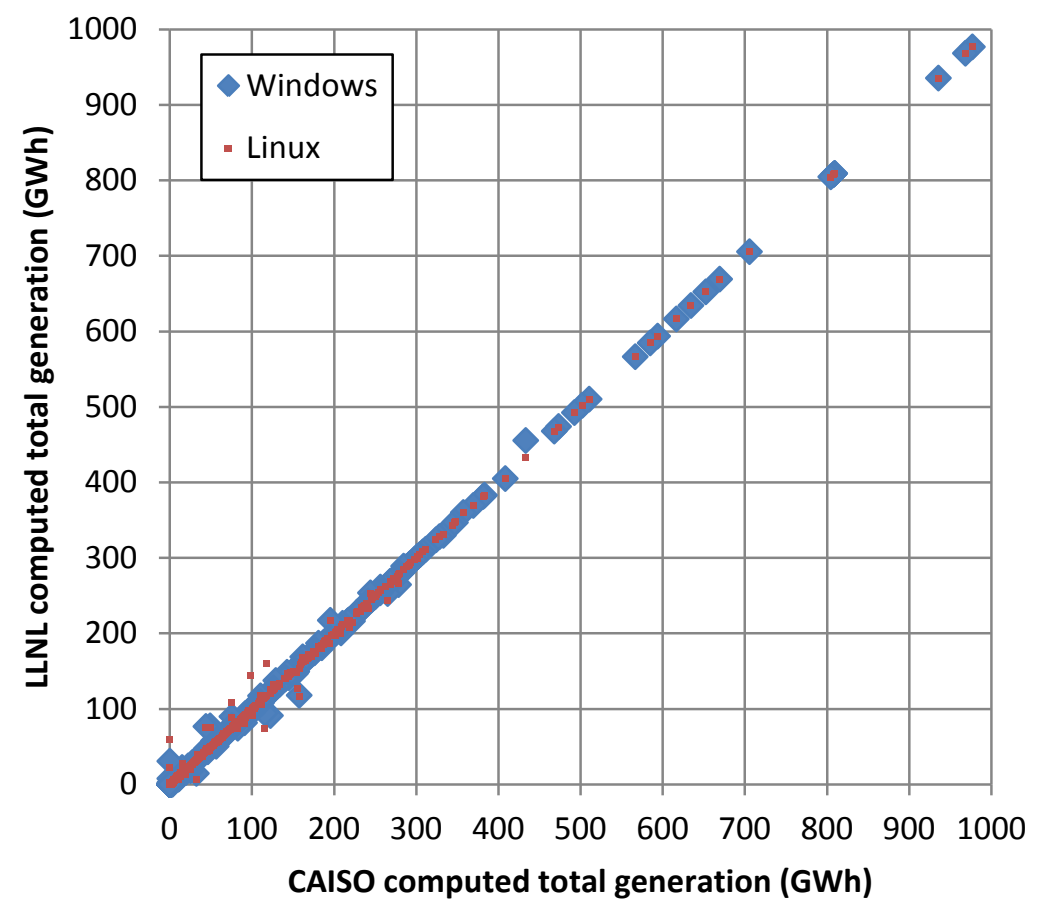

Figure 1.

Another output quantity used to compare the 3 sets of outputs was the generation price associated with each region. Figures 2, 3, and 4 show the on-peak, off-peak, and "all periods" price, respectively, for each WECC region as calculated in the 3 simulations. The regional prices do not vary significantly between the 3 simulations, with the greatest price deviation (relative to the CAISO simulation) of $0.22 \%$ for the LLNL Windows simulation and $0.18 \%$ for the LLNL Linux simulation. 


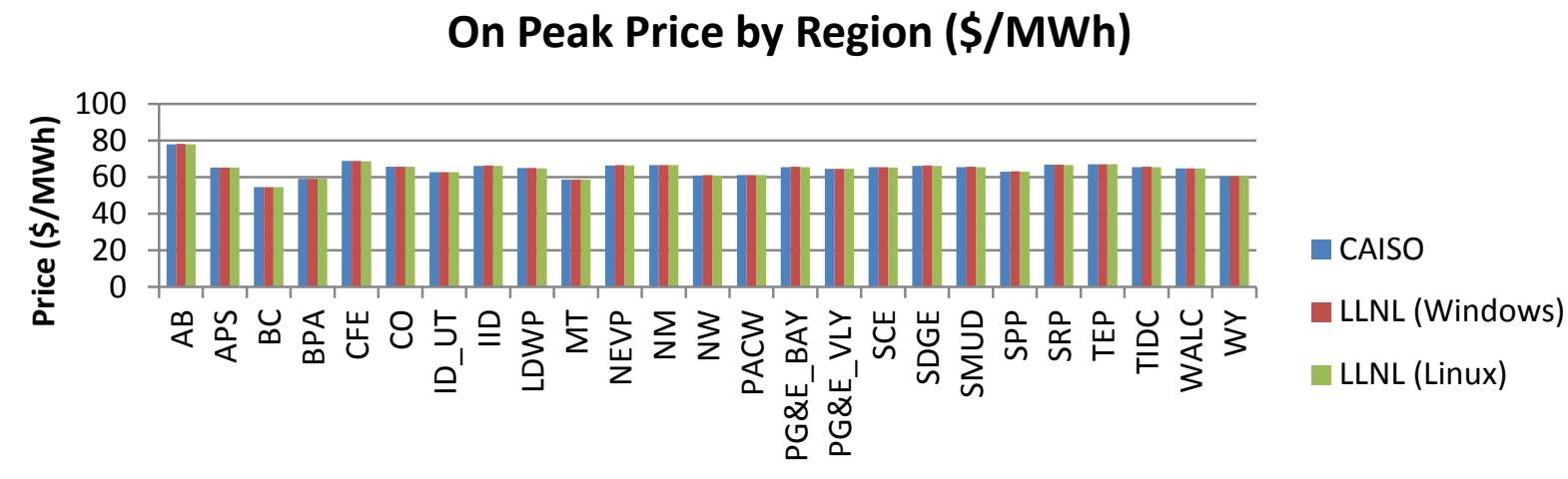

Region

Figure 2.

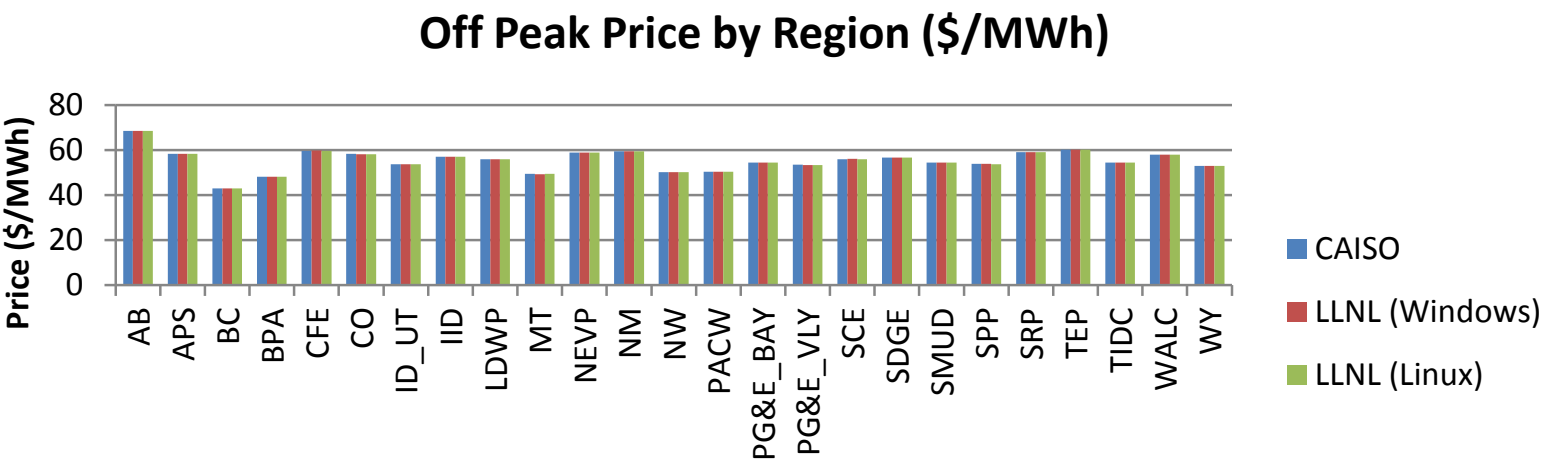

Region

Figure 3.

\section{All Periods Price by Region (\$/MWh)}

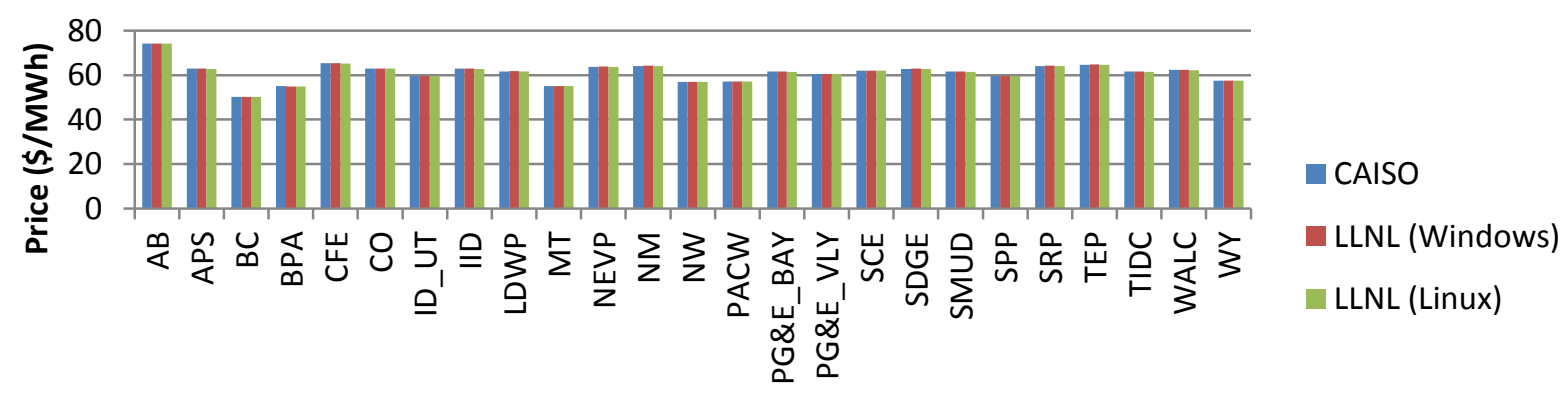

Region

Figure 4. 
In the course of this price comparison, the CAISO post-processed spreadsheet for this particular simulation was examined in detail. The first quantity summarized in the processed data spreadsheet was labeled marginal cost price (MCP). It was noted during the comparison process that the data labeled as MCP in CAISO's processed data spreadsheet in fact did not correspond to MCP output from the CAISO Plexos simulation, but many of the data did correspond to the Price output from the CAISO Plexos simulation. Thus the comparison was made for the Plexos "Price" output, rather than the MCP output.

\section{Discussion and Conclusions}

This report used two metrics to compare the output of the CAISO 33\% RPS Plexos model across three different computing platforms. The first metric compared total monthly generation broken down by generator and the second metric compared the generation price broken down my region. In both cases, relevant quantities differed by less than half a percentage. The small differences found between simulations is likely attributable to the different Plexos versions used, and the different MIP solvers used in the three cases. It is reasonable to assume, moving forward, that Plexos simulations performed at LLNL will likely generate similar solution sets to identical simulations performed by CAISO. 